\title{
Magnetic biochar from alkali-activated rice straw for removal of rhodamine $B$ from aqueous solution
}

\author{
Zhaogang Ren ${ }^{1}$, Fang Chen ${ }^{1}$, Bin Wang ${ }^{2}$, Zhongxian Song ${ }^{3}$, Ziyu Zhou ${ }^{1}$, Dong Ren $^{{ }^{\dagger}}$ \\ ${ }^{1}$ College of Environmental Science and Engineering, China West Normal University, Nanchong 637009, China \\ ${ }^{2}$ School of Environment and Resource, Southwest University of Science and Technology, Mianyang 621010, China \\ ${ }^{3}$ School of Municipal and Environmental Engineering, Henan University of Urban Construction, Pingdingshan, 467036, China
}

\begin{abstract}
To address organic dye wastewater, economic and effective adsorbents are required. Here, magnetic biochar from alkali-activated rice straw (AMBC) was successfully synthesized using one-step magnetization and carbonization method. The alkaline activation caused the large specific surface area, high pore volume and abundant oxygen-containing groups of the $\mathrm{AMBC}$, and the magnetization gave the AMBC a certain degree of electropositivity and fast equilibrium characteristics. These characteristics collectively contributed to a relative high adsorption capacity of $53.66 \mathrm{mg} \mathrm{g}^{-1}$ for this adsorbent towards rhodamine $\mathrm{B}(\mathrm{RhB})$. In brief, $\mathrm{RhB}$ can spontaneously adsorb onto the heterogeneous surface of the AMBC and reach the equilibrium in $60 \mathrm{~min}$. Although the initial $\mathrm{pH}$, ionic strength and other substances of the solution affected the adsorption performance of the $\mathrm{AMBC}$, it could be easily regenerated and reused with considerable adsorption content. Based on the results, $\mathrm{H}-\mathrm{bonds}, \pi-\pi$ stacking and electrostatic interactions were speculated as the primary mechanisms for $\mathrm{RhB}$ adsorption onto the AMBC, which was also demonstrated by the FTIR analysis. With the advantageous features of low cost, easy separation, considerable adsorption capacity and favorable stability and reusability, the AMBC would be a potential adsorbent for removing organic dyes from wastewater.
\end{abstract}

Keywords: Alkaline activation, Adsorption, Magnetic biochar, Rhodamine B, Rice straw

\section{Introduction}

With the rapid development of industry, more than one million tons of organic dyes are manufactured worldwide every year, and releasing of the dyes into natural waters is mostly through industrial effluents [1]. The discharged organic dyes have caused serious water pollution, and posed threat to the health of aquatic ecosystems and human beings [2, 3]. Rhodamine $\mathrm{B}(\mathrm{RhB})$, as one of the organic dyes, is widely used to impart color to paper, textile, leather, printing, food and other products. Subsequently, RhB may be released into the environment. As reported by previous studies, $\mathrm{RhB}$ is resistant to natural degradation, and can exert serious carcinogenicity, reproductive toxicity and neurotoxicity to animal $[4,5]$. Therefore, it is essential to remove $\mathrm{RhB}$ from wastewaters.

In recent years, various separation and transformation technologies such as adsorption, biological degradation and photolysis were developed to treat the organic dye wastewaters. Compared to other methods, adsorption has the advantages of time-saving, low cost, simple design and low energy consumption. Adsorption has been used to separate organic dyes from wastewaters, but traditional adsorbents limit its application at a large scale. For this reason, considerable efforts have been devoted by researchers to develop novel adsorbents. A large number of emerging materials, including biochar (BC), graphene oxide and multi-walled carbon nanotubes, are fabricated and applied for adsorption of organic dyes [6-8]. Among these materials, BC has been known as an innovative and promising adsorbent due to its numerous functional groups, good stability, high surface area, low cost, and easily accessible characteristics $[9,10]$. However, due to poor separation and regeneration of $\mathrm{BC}$, its application in wastewater treatment is very limited [11]. Furthermore, the BC released into natural waters may cause the secondary pollution by enhancing the migration and resuspension of pollutants in the sediments. Thus, synthesis of BC-based adsorbents overcoming those shortcomings is critical for its further industrial application.

Introduction of magnetic nanoparticles can remarkably overcome
This is an Open Access article distributed under the terms of the Creative Commons Attribution Non-Commercial License (http://creativecommons.org/licenses/by-nc/3.0/) which permits unrestricted non-commercial use, distribution, and reproduction in any medium, provided the original work is properly cited.

Copyright (C) 2020 Korean Society of Environmental Engineers
Received June 03, 2019 Accepted August 07, 2019

${ }^{\dagger}$ Corresponding author

Email: dren@cwnu.edu.cn

Tel: +86-817-256-8646 Fax: +86-817-256-8646

ORCID: 0000-0002-3302-1815 
the disadvantage of $\mathrm{BC}$ with respect to separation from solutions. $\mathrm{Fe}_{3} \mathrm{O}_{4}$ particles, feature merits in strongly magnetic properties, were previously loaded onto BC using several methods, including co-precipitation, hydrothermal reaction and microwave irradiation [7, 12, 13]. The composite prepared by co-precipitation is usually unstable under acidic condition, and hydrothermal and microwave reactions are time- and energy-consuming. Furthermore, magnetization and carbonization are two traditionally independent procedures for magnetic BC preparation. In recent years, the two processes were successfully incorporated into one step to cut the time and energy costs $[14,15]$. However, the adsorption performance of BC was sacrificed on a large scale due to the negative effects of magnetic particles. As reported previously, metal hydroxide coating and alkaline activation could effectively promote the adsorption performance of BC [16-18]. On this basis, we hypothesize that the introduction of alkaline activation procedure into magnetic BC synthesis may eliminate the negative effects from magnetization. To date, the information is still very limited on the preparation and application of the BC derived from alkali-activated biomass using one-step carbonization and magnetization method.

Herein, alkali-activated rice straw was used to synthesize the magnetic biochar (AMBC) by a facile method. The adsorption capacity, behavior and mechanisms of this material were systematically studied using RhB as a model organic dye. The influence of some aquatic environment factors such as $\mathrm{pH}$ and ionic strength was also explored on the adsorption of $\mathrm{RhB}$ to the AMBC. Finally, regeneration and reusability of the adsorbent were studied. The present study provides new insights into developing BC and advances its application in wastewater treatment.

\section{Material and Methods}

\subsection{Chemicals}

$\mathrm{RhB}$ was purchased from Sigma-Aldrich at a purity of 95\%. Sodium hydroxide $(\mathrm{NaOH})$, hydrochloric acid $(\mathrm{HCl})$, nitric acid $\left(\mathrm{HNO}_{3}\right)$, hydrogen fluoride (HF), hydrogen peroxide $\left(\mathrm{H}_{2} \mathrm{O}_{2}\right)$, sodium chloride $(\mathrm{NaCl})$, calcium chloride $\left(\mathrm{CaCl}_{2}\right)$ and ferric chloride hexahydrate $\left(\mathrm{FeCl}_{3} \cdot 6 \mathrm{H}_{2} \mathrm{O}\right)$ were purchased in analytical grade from Sinopharm Chemical Reagent Co., Ltd., China. All the chemicals were used as received without further purification. Ultrapure water $\left(18.2 \mathrm{M} \Omega \mathrm{cm}, 25^{\circ} \mathrm{C}\right)$ was prepared by a Milli-Q system in the laboratory.

\subsection{Adsorbents Synthesis}

Rice straws were collected from a cropland in Cangxi county October 2018, Sichuan province, China. The samples were cleaned and washed with tap water, air dried for four weeks and then chopped to pass through 10 mesh sieve.

The AMBC was synthesized using a method previously described with some modifications [14], as shown in Fig. S1. In brief, 50 $\mathrm{g}$ of the raw material was soaked in $500 \mathrm{~mL}$ of $\mathrm{NaOH}$ solution $\left(0.2 \mathrm{~mol} \mathrm{~L}^{-1}\right)$ for one hour. The alkali-activated straws were washed and then dispersed in $500 \mathrm{~mL}$ of $\mathrm{FeCl}_{3}$ solution $(1.0 \mathrm{~mol} \mathrm{~L}$ ) followed by heated at $50^{\circ} \mathrm{C}$ for another $30 \mathrm{~min}$. After that, the $\mathrm{Fe}^{3+}$ loaded straws were separated and washed three times with ultrapure water.
Finally, the modified straws were pyrolyzed at $650^{\circ} \mathrm{C}$ for $60 \mathrm{~min}$ under $\mathrm{N}_{2}$ atmosphere (200 $\mathrm{mL} \mathrm{min}{ }^{-1}$ ). The pyrolysis temperature was optimized by collectively considering the adsorption performance, magnetism strength and energy consumption of the AMBC. For comparison, BC was obtained by pyrolysis the raw straws with the same conditions, and magnetic biochar (MBC) was prepared by pyrolysis the $\mathrm{Fe}^{3+}$ loaded rice straw without alkaline activation.

\subsection{Material Characterization}

Composition of $\mathrm{C}, \mathrm{H}, \mathrm{O}$ and $\mathrm{N}$ of the $\mathrm{AMBC}$ was analyzed by an elemental analyzer (Elementar, Germany). For iron quantification, the AMBC was digested with $\mathrm{HNO}_{3}-\mathrm{H}_{2} \mathrm{O}_{2}-\mathrm{HF}$, and determined by an inductively coupled plasma atomic emission spectrophotometry (Agilent 7700s). The magnetic property was characterized on a vibrating sample magnetometer at room temperature (MPMS $\mathrm{XL}-5)$. The $\mathrm{pH}$ of zero point charge ( $\mathrm{pH}_{\mathrm{PZC}}$ ) was determined using a previously reported method [19]. The prepared BC and MBC were also characterized using the same methods to obtain their physicochemical properties.

The morphology of the ABMC was obtained using scanning electron microscopy (Zeiss Sigma 500). Briefly, $10 \mathrm{mg}$ of each adsorbent was dispersed in $20 \mathrm{~mL}$ pure water for $30 \mathrm{~min}$ and then picked up onto a carbon-coated copper grid. After being dried, the adsorbents were photographed under high vacuum at $30 \mathrm{kV}$ voltages. The Brunauer-Emmett-Teller (BET) method (ASAP 2460) was used to analyze the specific surface area, pore volume and pore diameter by nitrogen adsorption-desorption isotherm. Prior to measurement, the $\mathrm{AMBC}$ was outgassed at $300^{\circ} \mathrm{C}$ for $4 \mathrm{~h}$. Functional groups in the adsorbent were analyzed on a Fourier transform infrared (FTIR) spectroscopy (Varian 640) using a potassium bromide pellets technique [20].

\subsection{Adsorption Experiments}

Batch adsorption experiments were carried out in 40-mL glass vials with Teflon-lined caps in triplicate. To this end, the effects of contact time and initial concentration were pre-assessed on $\mathrm{RhB}$ removal. The adsorption kinetics of $\mathrm{RhB}$ was studied at $25^{\circ} \mathrm{C}$ with shaking at $180 \mathrm{rpm}$. Briefly, $40 \mathrm{mg}$ of the $\mathrm{AMBC}$ was added into $40 \mathrm{~mL}$ of $\mathrm{RhB}$ solution ( $50 \mathrm{mg} \mathrm{L} \mathrm{L}^{-1}, \mathrm{pH}=6.5 \pm 0.2$ ), and the samples were taken at selected time intervals for $\mathrm{RhB}$ quantification. The adsorption isotherms were obtained with $\mathrm{RhB}$ ranging from 10 to $100 \mathrm{mg} \mathrm{L}^{-1}$ at 10,25 and $40^{\circ} \mathrm{C}$, respectively.

To explore the influence of $\mathrm{pH}$ on $\mathrm{RhB}$ adsorption onto the $\mathrm{AMBC}$, the solutions were adjusted to a $\mathrm{pH}$ range of 2-11 using $2.0 \mathrm{~mol} \mathrm{~L} \mathrm{~L}^{-1} \mathrm{NaOH}$ and $\mathrm{HCl}$. The effect of ionic strength on RhB adsorption was investigated from 0.05 to 0.5 adjusted by $\mathrm{NaCl}$ and $\mathrm{CaCl}_{2}$ at $\mathrm{pH}=6.5$. Temperature for all the experiments was controlled at $25^{\circ} \mathrm{C}$, and the concentration of $\mathrm{RhB}$ was 50 $\mathrm{mg} \mathrm{L} \mathrm{L}^{-1}$. After adsorption equilibrium, samples were collected for RhB quantification. All of the experiments were performed in triplicate.

\subsection{Stability and Reusability of the AMBC}

The stability and reusability of the AMBC were evaluated by the cycle number-dependent removal rate of $\mathrm{RhB}$, and a total of 3 cycles were carried out. Briefly, the adsorption performance was 
tested by mixing $40 \mathrm{mg}$ of the $\mathrm{AMBC}$ with $40 \mathrm{~mL}$ of $\mathrm{RhB}$ solution $\left(50 \mathrm{mg} \mathrm{L}^{-1}\right.$ ) at $\mathrm{pH}=6.5$. After a $60 \mathrm{~min}$ shaking at room temperature, the $\mathrm{AMBC}$ was recovered using a magnet. It was then dispersed in $40 \mathrm{~mL}$ methanol-water solution (v/v, 7:3) and sonicated for 10 $\mathrm{min}$. After that, the regenerated adsorbents were magnetically separated from the solution, washed thoroughly with ultrapure water, vacuum dried and used for subsequent adsorption. To further evaluate the regeneration and reusability of the AMBC in practical application, the cycle number-dependent removal rate of $\mathrm{RhB}$ was determined in a model textile effluent synthetized according to the OECD guidelines. Briefly, the synthetic wastewater was consisted by (per liter of tap water): $160 \mathrm{mg}$ of peptone, $110 \mathrm{mg}$ of meat extract, $30 \mathrm{mg}$ of urea, $28 \mathrm{mg}$ of $\mathrm{K}_{2} \mathrm{HPO}_{4}, 7 \mathrm{mg}$ of $\mathrm{NaCl}$, $4 \mathrm{mg}$ of $\mathrm{CaCl}_{2} \cdot 2 \mathrm{H}_{2} \mathrm{O}, 2 \mathrm{mg}$ of $\mathrm{MgSO}_{4} \cdot 7 \mathrm{H}_{2} \mathrm{O}$ and $50 \mathrm{mg}$ of $\mathrm{RhB}$.

\subsection{RhB Quantification}

The absorbance of RhB in the solutions was determined by an UV-vis spectrometer (UV-2600, Shimadzu) at a wavelength of 554 $\mathrm{nm}$. The concentration of $\mathrm{RhB}$ was calculated using a correction curve with an adjusted $R^{2}>0.999$ in $0.2-20 \mathrm{mg} \mathrm{L}^{-1}$ (Fig. S2). The amount of $\mathrm{RhB}$ adsorbed by the adsorbents at time $t$ and equilibrium was calculated using the Eq. (1) and (2).

$$
\begin{aligned}
& q_{t}=\left(C_{o}-C_{t}\right) \times V / m \\
& q_{e}=\left(C_{o}-C_{e}\right) \times V / m
\end{aligned}
$$

where $C_{0}, C_{\mathrm{e}}$, and $C_{\mathrm{t}}\left(\mathrm{mg} \mathrm{L}^{-1}\right)$ are the initial concentration, equilibrium concentration, and concentration of $\mathrm{RhB}$ at time $t$ (min), respectively. $m$ is the mass of the adsorbent (g), and $V$ is the volume of the solution (L).

\subsection{Data Analysis}

Pseudo-first and -second order kinetic models, shown as Eq. (3) and (4), were used to describe the adsorption mechanisms of $\mathrm{RhB}$. In addition, a diffusion model as Eq. (5) was applied to evaluate the influence of diffusion process on the adsorption kinetics.

$$
\begin{gathered}
q_{t}=q_{e}\left(1-e^{-k_{1} t}\right) \\
q_{t}=q_{e}^{2} k_{2} t\left(1+q_{e} k_{2} t\right)^{-1} \\
q_{t}=q_{e} k t^{1 / 2}+C
\end{gathered}
$$

where $q_{\mathrm{t}}\left(\mathrm{mg} \mathrm{g}^{-1}\right)$ is the adsorption amount at time $t$ (min), and $q_{\mathrm{e}}\left(\mathrm{mg} \mathrm{g}^{-1}\right)$ is the adsorption capacity at equilibrium. $k_{1}\left(\mathrm{~min}^{-1}\right)$, $k_{2}\left(\mathrm{~g} \mathrm{mg}^{-1} \mathrm{~min}^{-1}\right)$ and $k\left(\mathrm{~g} \mathrm{mg}^{-1} \mathrm{~min}^{-0.5}\right)$ are the rate constants. $C$ is a constant for the intra-particle diffusion model.

The adsorption isotherms were descried using Freundlich and Langmuir models, as Eq. (6) and (7).

$$
\begin{gathered}
q_{e}=K_{F} C_{e}^{1 / n} \\
q_{e}=q_{\mathrm{max}} K_{L} C_{e}\left(1+K_{L} C_{e}\right)^{-1}
\end{gathered}
$$

where $q_{\mathrm{e}}$ is defined to be the same as above, and $C_{\mathrm{e}}$ is the RhB equilibrium concentration $\left(\mathrm{mg} \mathrm{L}^{-1}\right) ; q_{\max }\left(\mathrm{mg} \mathrm{g}^{-1}\right)$ is the maximum adsorption capacity; $1 / \mathrm{n}$ is an empirical constant of the Freundlich model; $K_{\mathrm{F}}\left(\left(\mathrm{mg} \mathrm{g}^{-1}\right)\left(\mathrm{mg} \mathrm{L}^{-1}\right)^{\mathrm{n}}\right)$ and $K_{\mathrm{L}}\left(\mathrm{L} \mathrm{mg}^{-1}\right)$ are the Freundlich and Langmuir adsorption affinity parameter, respectively.

The thermodynamic parameters including standard free energy change $\left(\Delta G^{0}\right)$, entropy change $\left(\Delta S^{0}\right)$ and enthalpy change $\left(\Delta H^{0}\right)$ were calculated using Eq. (8) and (9).

$$
\triangle G^{o}=-R T \ln K^{o}
$$

$$
\triangle H^{o}=T \triangle S^{o}-R T \ln K^{o}
$$

where $R\left(8.314 \mathrm{~J} \mathrm{~mol}^{-1} \mathrm{~K}^{-1}\right)$ is the universal gas constant, and $T(K)$ is the thermodynamic temperature for the systems. $K^{0}$ is the adsorption equilibrium constant.

\section{Results and Discussion}

\subsection{Characteristics of the Adsorbents}

The AMBC possessed abundant cracks and porosity on its surface (Fig. 1(a) and (b)). The isotherms (Fig. 1(c)) were determined as type IV for the AMBC, which was the characteristics of mesoporous material and the reason for the significant volume of nitrogen adsorbed at relative high pressure $[14,21]$. The specific surface area was measured as $396.9 \mathrm{~m}^{2} \mathrm{~g}^{-1}$ for the $\mathrm{AMBC}$, about 2.0 and 1.4 times larger than that of the $\mathrm{BC}$ and $\mathrm{MBC}$ (Table S1). According to the result of dynamic light scattering analysis, about 34.41\%, 54.76\% and $10.94 \%$ of the AMBCs were $250-400 \mathrm{~nm}, 400-550 \mathrm{~nm}$ and $550-850$ $\mathrm{nm}$, and the average particle size was $466.87 \mathrm{~nm}$ (Fig. 1(d)). The energy dispersive spectroscopy analysis confirmed that iron was successfully introduced into the biochar (Fig. 1(e)). The iron content of the AMBC was quantified as $37.49 \mathrm{mg} \mathrm{g}^{-1}$, and most of the iron formed the magnetic composition because the AMBC has strong magnetism about $3.12 \mathrm{emu} \mathrm{g}^{-1}$, as shown in Fig. S3.

The $\mathrm{C}, \mathrm{H}, \mathrm{O}, \mathrm{N}$ and $\mathrm{S}$ contents of the AMBC were $76.48 \%$, $2.67 \%, 16.20 \%, 0.16 \%$ and $0.08 \%$, respectively, which was similar to the composition of BCs reported by other researchers [22]. Compared to the $\mathrm{BC}$ and $\mathrm{MBC}$, the carbon content of the AMBC was slightly lower, but the oxygen content was higher (Table S1). This result could be explained by the enhanced release of carbonaceous volatiles due to the magnetization and alkaline activation used in the preparation processes.

The pHpzc of the $\mathrm{BC}$ was significantly changed by the treatments of alkaline activation and magnetization (Fig. S4). The pHpzc of maghemite mainly comprised by $\mathrm{FeOH}_{2}{ }^{+}$was reported to be 6.5 or higher [23]. Thus, the increased pHpzc for the MBC and AMBC, compared to the $\mathrm{BC}$, was primarily derived from the magnetization process. Based on the result of the elemental analysis, alkaline activation introduced of more oxygen-containing groups, which would contribute to the lower pHpzc of the AMBC than the MBC. These results collectively indicated that the AMBC was successfully synthesized from the alkali-activated rice straws using one-step magnetization and carbonization method. 

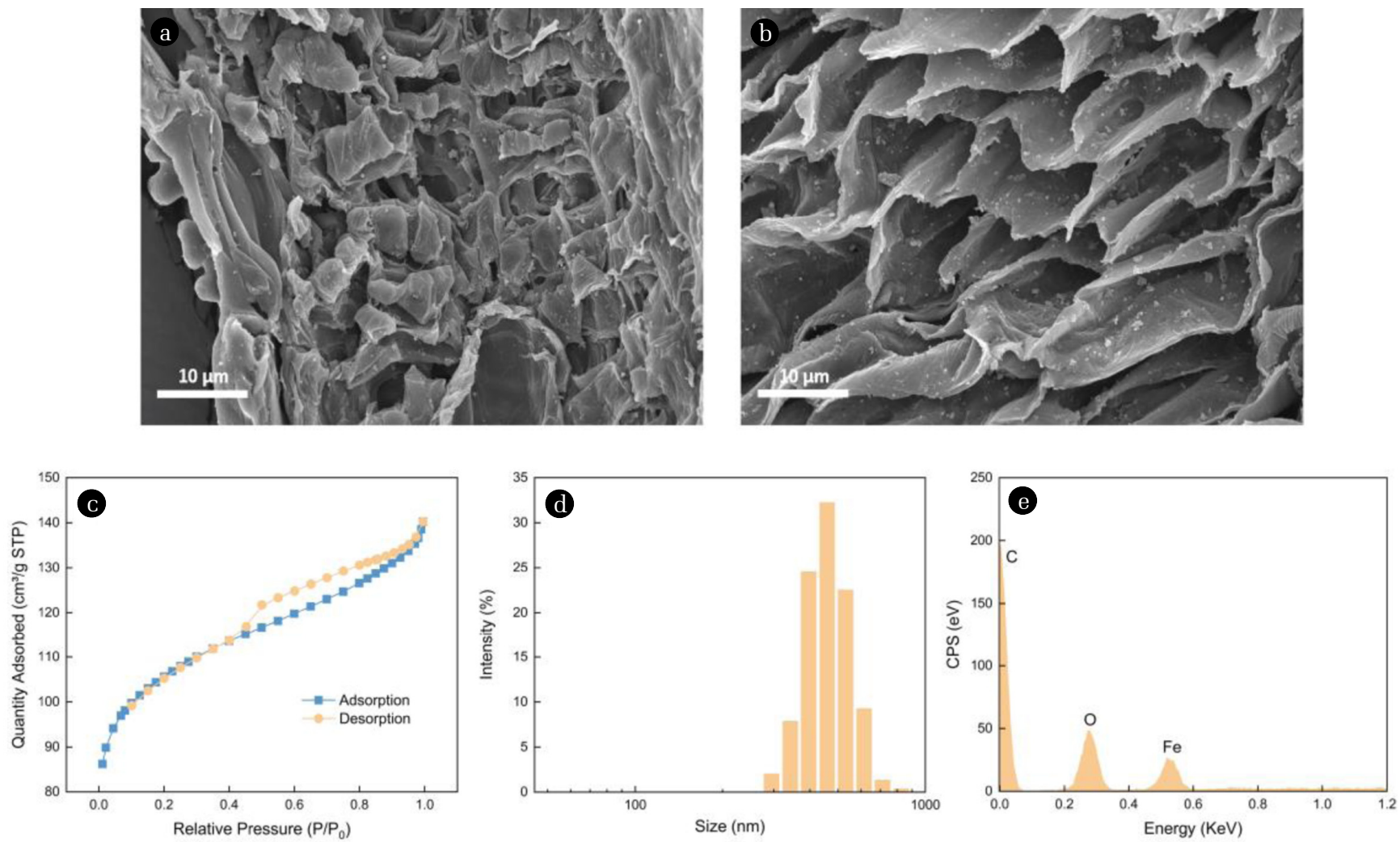

Fig. 1. (a), (b) The SEM images, (c) Nitrogen adsorption-desorption isotherm, (d) Dynamic light scattering spectra and (e) Energy dispersive pattern of the AMBC.

\subsection{RhB Adsorption Kinetics}

To explore the adsorption rate of $\mathrm{RhB}$ onto the $\mathrm{AMBC}$ and the time required for reaching adsorption equilibrium, adsorption kinetics were investigated. As shown in Fig. 2(a), a rapid adsorption of $\mathrm{RhB}$ onto the AMBC occurred during the first $5 \mathrm{~min}$, and the adsorption capacity reached about $90 \%$ of its maximum. After that, a slow process until adsorption equilibrium was reached about 60 min. Similarly, magnetic biochar was also determined to reach equilibrium more rapid than BCs in adsorption of $17 \beta$-estradiol, hexavalent chromium and other pollutants [14, 24]. Based on the results, $60 \mathrm{~min}$ was chosen as the contact time to achieve equilibrium for the further adsorption studies. Compared to the adsorption performance of magnetic active carbon, carbon nanotubes and other carbon materials [25-27], the time required for reaching adsorption equilibrium was much shorter for the AMBC. This might be assigned to the porous structures on this material, enabling easy and fast access of RhB to the adsorption sites [28].

The adsorption process was further analyzed using pseudo-first and -second order models as Eq. (3) and (4). The pseudo-second order model can describe the adsorption of $\mathrm{RhB}$ onto the AMBC more precisely with relatively higher adjusted determination coefficient $\left(R_{A d j}^{2}\right.$ ), as listed in Table S2. It indicated that the chemical adsorption would be the rate-limiting mechanism for RhB adsorption onto the adsorbent. It is interesting that the pseudo-second order model was also suitable for describing the adsorption of $\mathrm{RhB}$ onto the $\mathrm{BC}$ and MBC (Fig. S5), meaning that the alkaline activation and magnetization did not change the adsorption kinetics pattern. Similar results were also reported by previous studies performed to explore the feasibility of using BC and magnetic BC derived from biomass to remove organic pollutants from aqueous solution [29, 30]. For pseudo-second order model, the initial adsorption rate $r$ (mg $(\mathrm{g} \mathrm{min})^{-1}$ ) is proportion to the adsorption equilibrium capacity and can be calculated using the equation as $r=k_{2} q_{e}^{2}$ [31]. The value of $r$ for the AMBC was much higher than that of the BC but lower than that of the MBC (Table S2). Thus, the magnetization was the primary driving force for the fast mass transfer of $\mathrm{RhB}$ from bulk solution onto the AMBC.

Intra-particle diffusion model as Eq. (5) was fitted to identify the mass transfer resistance for RhB adsorption onto the AMBC. If the value of $C$ in the model equals zero, the adsorption rate is controlled by intra-particle diffusion for the whole process [32]. As shown in Fig. 2(b), the adsorption of RhB onto the AMBC was comprised by three stages. The first sharper slope represents the film diffusion process for RhB from bulk solution to the AMBC surface. The second part is the result of the intra-particle diffusion of $\mathrm{RhB}$. The last part is the equilibrium stage, i.e., the adsorption of $\mathrm{RhB}$ onto the internal surface of the adsorbent. Therefore, intra-particle diffusion was present as one part of $\mathrm{RhB}$ adsorption onto the $\mathrm{AMBC}$, but it was not the rate-limiting step for the whole process. Due to failure to obtain the data of the fast diffusion phase, two parts were fitted for the adsorption process of $\mathrm{RhB}$ onto the MBC (Fig. S6). However, the whole adsorption process would be 

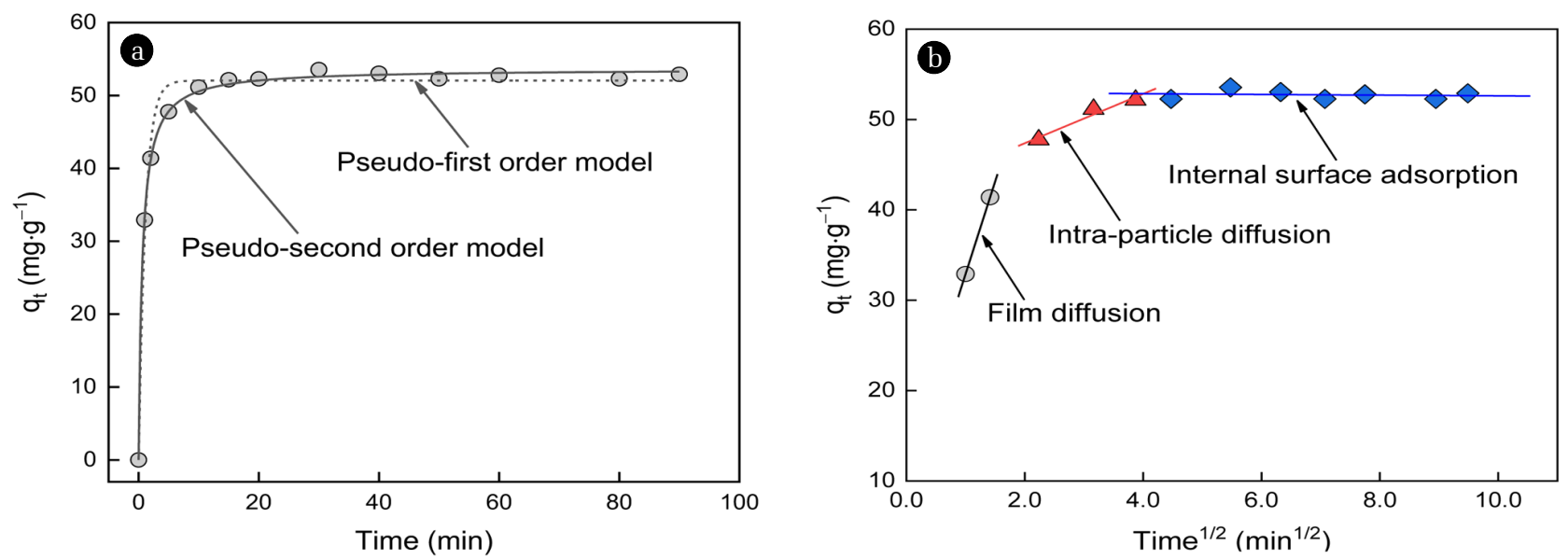

Fig. 2. Adsorption kinetics and (a) Intra-particle diffusion model (b) for RhB by the $A M B C$. Experimental conditions were controlled as $C_{A M B C}$ $=1.0 \mathrm{mg} \mathrm{mL}^{-1}, \mathrm{C}_{\mathrm{RhB}}=50.0 \mathrm{mg} \mathrm{L}^{-1}, \mathrm{pH}=6.5$ and temperature $=25^{\circ} \mathrm{C}$.

still comprised by three stages because the intercept of the first fitted stage was about $30 \mathrm{mg} \mathrm{g}^{-1}$. It should be noted that the diffusion and adsorption of $\mathrm{RhB}$ onto the BC (Fig. S6) were distinctively different from that onto the MBC and AMBC. These results demonstrated that the alkaline activation and magnetization indeed altered the mass transfer mechanisms for $\mathrm{RhB}$ adsorption onto the $\mathrm{BC}$.

\subsection{RhB Adsorption Isotherms}

The adsorption isotherms of $\mathrm{RhB}$ at different temperatures to the AMBC are displayed in Fig. 3, and the fitted parameters are listed in Table 1. The adsorption isotherms can provide insights into the distribution characteristics of adsorbates to the adsorbents. The Langmuir model assumes that pollutant adsorbs as monolayer onto a homogeneous surface, while the Freundlich model was derived on an exactly opposite position [33]. In this study, the Freundlich model was superior than the Langmuir model in describing the adsorption behaviors of $\mathrm{RhB}$ onto the $\mathrm{AMBC}$ based on the adjusted $R^{2}$ values. It indicated the diversity of adsorption sites on the adsorbent. Similar phenomena were found for the adsorption of RhB to the MBC and BC (Fig. S7). Therefore, the three adsorbents had similar adsorption thermodynamic characteristics toward $\mathrm{RhB}$.

The adsorption capacity of the AMBC towards $\mathrm{RhB}$ increased with the increment of $\mathrm{RhB}$ concentration and reaction temperature. Specifically, $K_{\mathrm{F}}$ was calculated as $12.56,16.28$ and 17.68 at 10 ,
25 and $40^{\circ} \mathrm{C}$, respectively. Similar results were also reported by other researchers when studying the adsorption performance of the pristine and modified biochars [34, 35].

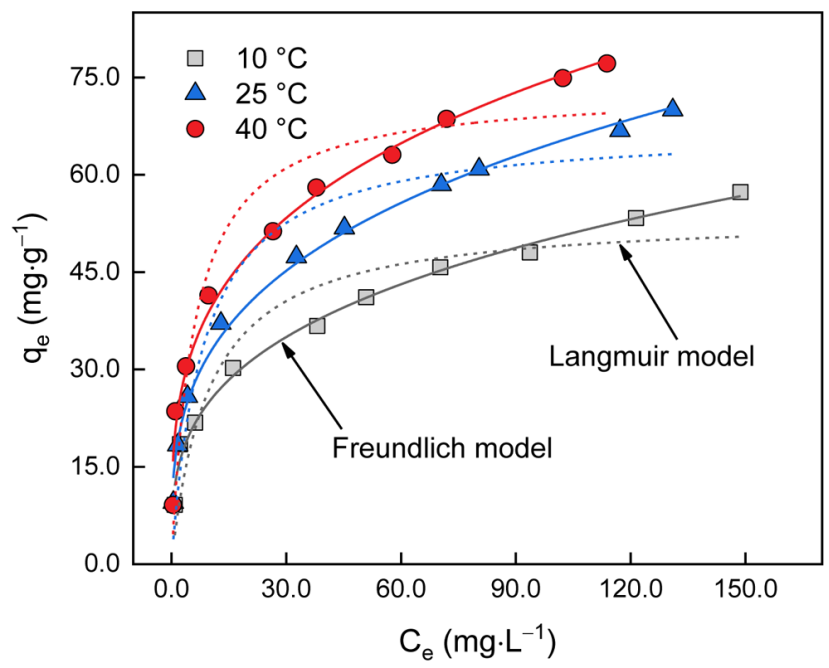

Fig. 3. Adsorption isotherms for $\mathrm{RhB}$ by the $\mathrm{AMBC}$ at $10^{\circ} \mathrm{C}, 25^{\circ} \mathrm{C}$ and $40^{\circ} \mathrm{C}$. The $\mathrm{C}_{\mathrm{AMBC}}=1.0 \mathrm{mg} \mathrm{mL}^{-1}, \mathrm{C}_{\mathrm{RhB}}=50.0 \mathrm{mg} \mathrm{L}^{-1}, \mathrm{pH}=$ 6.5 and equilibrium time $=60 \mathrm{~min}$.

Table 1. Freundlich and Langmuir Isotherms Parameters for the Adsorption of RhB onto the AMBC

\begin{tabular}{|c|c|c|c|c|}
\hline \multirow{2}{*}{ Models } & \multirow{2}{*}{ Parameters } & \multicolumn{3}{|c|}{ Temperature $\left({ }^{\circ} \mathrm{C}\right)$} \\
\hline & & 10 & 25 & 40 \\
\hline \multirow[t]{3}{*}{ Freundlich Model } & $K_{\mathrm{F}}\left(\left(\mathrm{mg} \mathrm{g}^{-1}\right) \cdot\left(\mathrm{L} \mathrm{mg}^{-1}\right)^{\mathrm{n}}\right)$ & 12.56 & 16.28 & 17.68 \\
\hline & $1 / \mathrm{n}$ & 0.301 & 0.296 & 0.302 \\
\hline & Adjusted $R^{2}$ & 0.991 & 0.992 & 0.981 \\
\hline \multirow[t]{3}{*}{ Langmuir Model } & $\mathrm{Q}_{\mathrm{m}}\left(\mathrm{mg} \mathrm{g}^{-1}\right)$ & 53.78 & 66.45 & 73.47 \\
\hline & $K_{\mathrm{L}}\left(\mathrm{L} \mathrm{mg}^{-1}\right)$ & 0.102 & 0.125 & 0.125 \\
\hline & Adjusted $R^{2}$ & 0.893 & 0.938 & 0.910 \\
\hline
\end{tabular}


Although similar thermodynamic behaviors were found for the $\mathrm{MBC}$ and BC (Table S3), the maximum adsorption capacity of the $\mathrm{MBC}$ and $\mathrm{BC}$ towards $\mathrm{RhB}$ was much lower than that of the AMBC. It demonstrated that alkaline activation was primarily responsible for the enhancement of the adsorption capacity. Compared to the BCs pyrolyzed from other biomass such as earthworm manure, corn straw and Pongamia glabra seed cover [6, 36, 37], the AMBC also exhibited an excellent adsorption performance. Therefore, the alkaline activation is indeed responsible for the high adsorption capacity of the AMBC, which might be attributed to its large specific surface area, abundant porous structure and specific reaction sites.

The thermodynamic parameters for the adsorption of $\mathrm{RhB}$ onto the AMBC were calculated, and the results were shown in Table 2. The $\Delta G^{0}$ was negative for the AMBC at all the temperatures, indicating that the adsorption processes were spontaneous. With temperature increasing from $10^{\circ} \mathrm{C}$ to $40^{\circ} \mathrm{C}$, the $\Delta G^{0}$ values gradually decreased, meaning that the higher temperature could facilitate the adsorption of $\mathrm{RhB}$ onto the AMBC. Similar trend was also found with the BC (Table S4), but the values were significantly lower than that of the AMBC. It was the reason why the adsorption capacities of the $\mathrm{BC}$ and $\mathrm{MBC}$ smaller than that of the AMBC. The positive values of $\Delta H^{0}$ indicated that the adsorption of RhB onto the AMBC was an endothermic process. This was the reason why the adsorption capacity increased with the enhancement of the reaction temperature. The positive values of $\Delta S^{0}$ represented the increased randomness at the interfaces in the adsorption progress. These behaviors of $\mathrm{RhB}$ adsorption to the AMBC agreed with the adsorption of $\mathrm{Pb}^{2+}$, Congo red, Titan yellow and other pollutants onto the biomass-derived MBC [38, 39].

Table 2. Thermodynamic Parameters for the Adsorption of RhB onto the $\mathrm{AMBC}$

\begin{tabular}{|c|c|c|c|}
\hline $\begin{array}{l}\text { Temperature } \\
\left({ }^{\circ} \mathrm{C}\right)\end{array}$ & $\begin{array}{c}\Delta \mathrm{G}^{0} \\
\left(\mathrm{~kJ} \mathrm{~mol}^{-1}\right)\end{array}$ & $\begin{array}{c}\Delta \mathrm{H}^{0} \\
\left(\mathrm{~kJ} \mathrm{~mol}^{-1}\right)\end{array}$ & $\begin{array}{c}\Delta S^{0} \\
\left(k J \mathrm{~mol}^{-1} K^{-1}\right)\end{array}$ \\
\hline 10 & -8.78 & & \\
\hline 25 & -9.93 & 8.32 & 0.06 \\
\hline 40 & -10.60 & & \\
\hline
\end{tabular}

\subsection{RhB Adsorption Affected by Hydro-Chemical Factors}

\subsubsection{Influence of $\mathrm{pH}$}

$\mathrm{pH}$ is one of the important factors affecting the adsorption process in liquid phase, which can markedly change the speciation of the adsorbates and the surficial properties of the adsorbents. In this study, the adsorption capacity of the AMBC was first increased with $\mathrm{pH}$ increased from 2.0 to 4.0 , and then decreased with $\mathrm{pH}$ further increasing (Fig. 4(a)). Thus, the $\mathrm{pH}$ condition of 4.0 is conducive to remove $\mathrm{RhB}$ from wastewater by this material. This phenomenon might be caused by the variation of the surface charge of the AMBC and the speciation of $\mathrm{RhB}$ at different $\mathrm{pH}$ levels. In terms of the detected $\mathrm{pH}_{\mathrm{zpc}}$, the surface of the $\mathrm{AMBC}$ is positively charged at $\mathrm{pH}<4.4$ and negatively charged at $\mathrm{pH}>4.4$. With a dissociation constant $\mathrm{pKa}$ of 3.7 [40], $\mathrm{RhB}$ molecules exist predominantly in cationic form at $\mathrm{pH}<3.0$ and in zwitterion form at $\mathrm{pH}>5.0$. The electrostatic attraction might contribute to the maximum
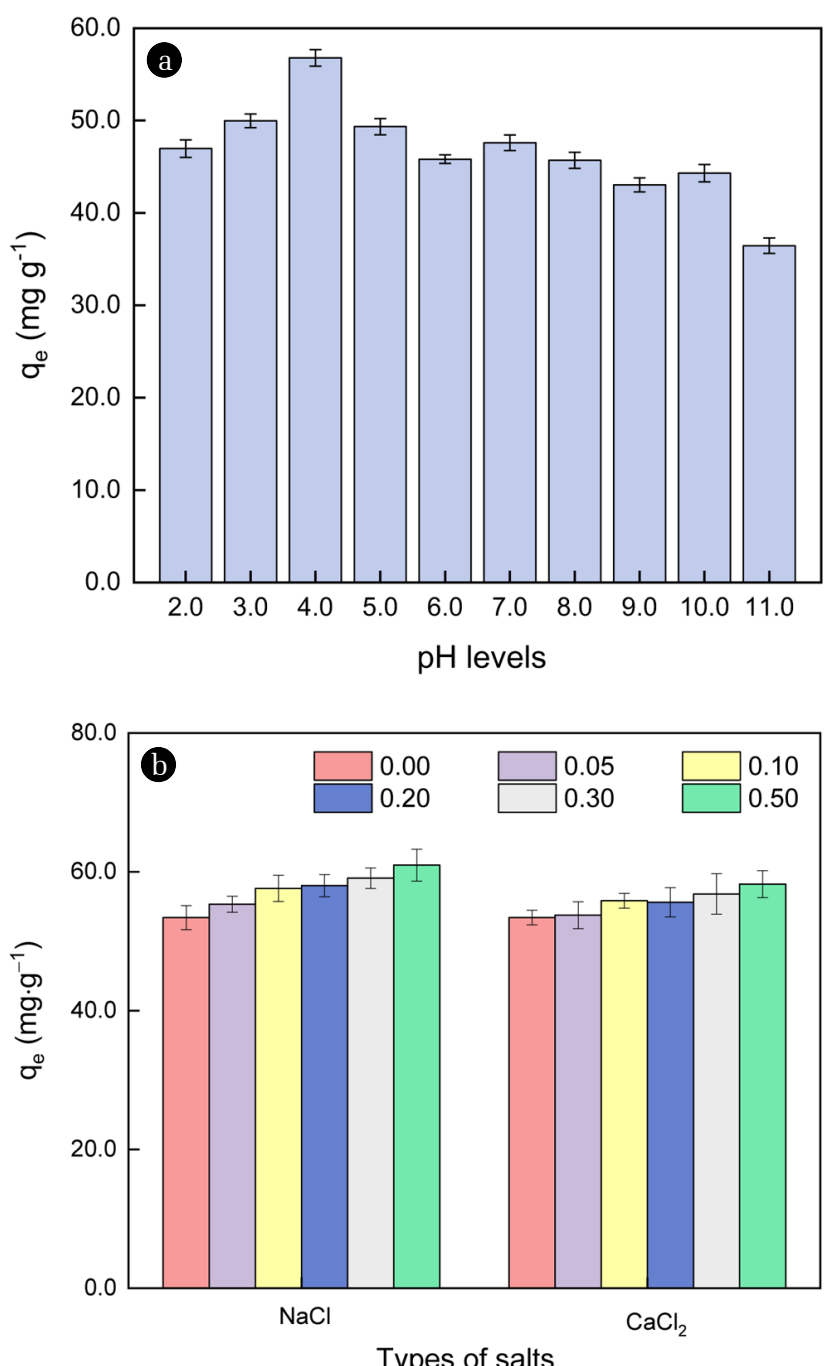

Fig. 4. Effects of $\mathrm{pH}$ and (a) lonic strength (b) on the adsorption of RhB by the AMBC. $C_{\text {RhB }}=50 \mathrm{mg} \mathrm{L}^{-1}, \mathrm{C}_{\mathrm{AMBC}}=1.0 \mathrm{mg} \mathrm{mL}^{-1}$, $\mathrm{pH}=6.5, \mathrm{~T}=25^{\circ} \mathrm{C}, t=60 \mathrm{~min}$.

sorption capacity of the $\mathrm{AMBC}$ at $\mathrm{pH}=4.0$, and the electrostatic repulsion would hinder $\mathrm{RhB}$ adsorption onto the surface of the AMBC under the strong acidic and alkaline conditions. It should be noted that the surface oxygen containing groups of the AMBC could also contribute to its excellent adsorption affinity with $\mathrm{RhB}$ by forming H-bonds. Thus, the breaking of the H-bonds would also reduce the adsorption of $\mathrm{RhB}$ onto the AMBC under alkaline conditions.

\subsubsection{Influence of ionic strength}

High content of salts in solutions is known to affect the adsorption of chemicals to adsorbents. In this study, $\mathrm{NaCl}$ and $\mathrm{CaCl}_{2}$ were used to evaluate the influence of ionic strength on the uptake of RhB by the AMBC. It can be seen from Fig. 4(b), the adsorption of $\mathrm{RhB}$ onto the adsorbent was slightly enhanced in the presence of $\mathrm{Na}^{+}, \mathrm{Ca}^{2+}$ and $\mathrm{Cl}^{-}$. In general, the adsorption processes at the solid/liquid interface could be affected by the increased ionic 
strength as a result of the salting out and the squeezing out effects $[41,42]$. The salting out effect was previously found to promote the adsorption of $17 \beta$-estradiol onto magnetic biochars at a concentration of $\mathrm{NaCl}$ below $0.01 \mathrm{~mol} \mathrm{~L}^{-1}$, but it was subsequently neutralized by the squeezing out effect at high $\mathrm{NaCl}$ concentration [31]. Thus, the enhanced adsorption capacity of the AMBC towards $\mathrm{RhB}$ in the salts solutions might be caused by the salting out effect. It should be noted that the adsorption capacity of the AMBC in $\mathrm{NaCl}$ solutions was always higher than that in $\mathrm{CaCl}_{2}$ solutions at the same ionic strength. This might be attributed to the relative high salt concentration when the ionic strength was adjusted by $\mathrm{NaCl}$. These results ascertained that the cation and anion in the solutions concurrently dominated the adsorption performance of the AMBC.

\subsection{Stability and Regeneration of the AMBC}

In this study, a $50 \%$ of methanol solution was used for desorption of $\mathrm{RhB}$ from the AMBC on the basis of large dissolution of $\mathrm{RhB}$ in the organic solvent. The adsorption-desorption cycles demonstrated that the used AMBC could be easily regenerated by the methanol solution, without significant loss in the adsorption capacity after 3 cycles in pure water (Fig. 5). However, the removal efficiency of $\mathrm{RhB}$ from the simulated wastewater decreased to $71.6 \%$ after 3 cycles, which is significantly lower than that of $\mathrm{RhB}$ in pure water (92.7-98.3\%). This might be caused by the complexity of the matrix, i.e., the cations, anions and other organic pollutants co-existed in the solutions may compete the adsorption sites [38]. Nevertheless, the adsorption performance of the AMBC was still considerable for industrial application. Therefore, the synthesized AMBC could be used as an alternative for removal of organic dyes from wastewaters.

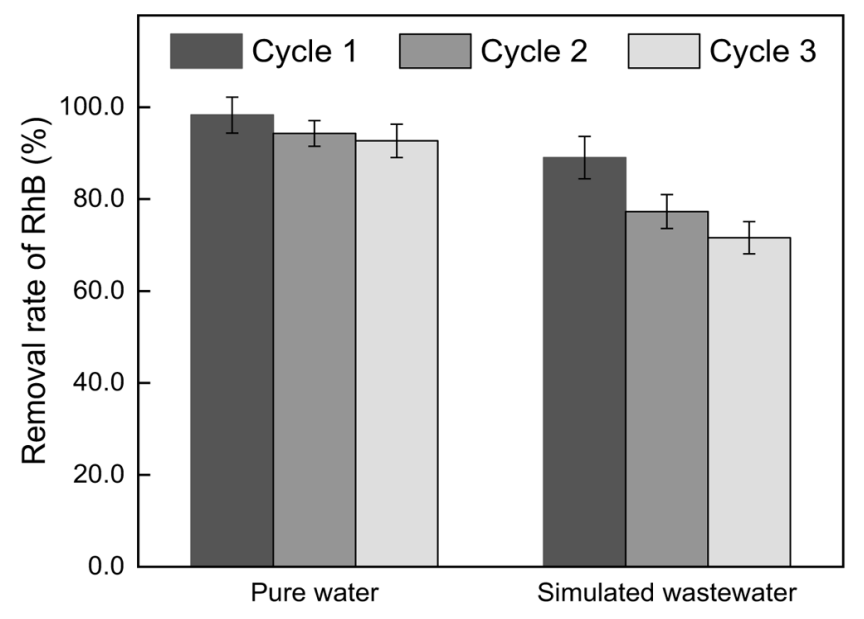

Solution types of RhB

Fig. 5. Evaluating the reusability and stability of the AMBC in pure water and simulated wastewater.

\subsection{Mechanisms for RhB Adsorption onto the AMBC}

The closeness of the RhB adsorption data to Freundlich isotherm indicated multi-layer adsorption onto the heterogeneous surface of the AMBC. The porous structures of the AMBC facilitated the physical adsorption of RhB, which was corroborated by the calculated $\Delta G$ value $\left(<40 \mathrm{~kJ} \mathrm{~mol}^{-1}\right)$. Meanwhile, the chemical adsorption processes such as H-bonds and electrostatic interactions were also involved in the processes. These mechanisms were demonstrated by the effects of $\mathrm{pH}$ and ionic strength on the adsorption of $\mathrm{RhB}$ onto the AMBC and the excellent fitness of pseudo-second order kinetics model to the adsorption data.

To further elucidate the mechanisms for $\mathrm{RhB}$ adsorption onto the AMBC, FTIR measurements were compared between the pristine and RhB-loaded AMBC (Fig. 6). The slightly increase in the absorption at $3,430-3,450 \mathrm{~cm}^{-1}$ could be assigned to the $\mathrm{O}-\mathrm{H}$ stretching of hydroxyl groups [43]. The peaks at 1,560, 1,028 and $490 \mathrm{~cm}^{-1}$ were ascribed to $\mathrm{C}=\mathrm{C}, \mathrm{C}-\mathrm{O}$ and $\mathrm{Fe}-\mathrm{O}$ vibrations in the $\mathrm{AMBC}$, respectively. Compared to the AMBC, the AMBC- $\mathrm{RhB}$ composite presented two new absorption peaks at 1,720 and $813 \mathrm{~cm}^{-1}$, corresponding to the stretching vibrations of $\mathrm{C}=\mathrm{O}$ and $\mathrm{N}-\mathrm{C}$ of the $\mathrm{RhB}$ molecule. Therefore, it is reasonable to speculate that the $\mathrm{RhB}$ was adsorbed onto the AMBC by H-bonds. Furthermore, these peaks were shifted by the adsorption of RhB, which indicated that $\pi-\pi$ stacking was also involved in the adsorption processes. Similar phenomena were also found with $17 \beta$-estradiol and polycyclic aromatic hydrocarbons adsorbing onto graphene oxide [44, 45]. It should be noted that the hydrophobic distribution is a universal interaction between organic pollutants and carbon materials [20, 45 , but it might be a less important contributor for $\mathrm{RhB}\left(\log K_{\mathrm{OW}}\right.$ $=2.38$ ) adsorption onto the AMBC.

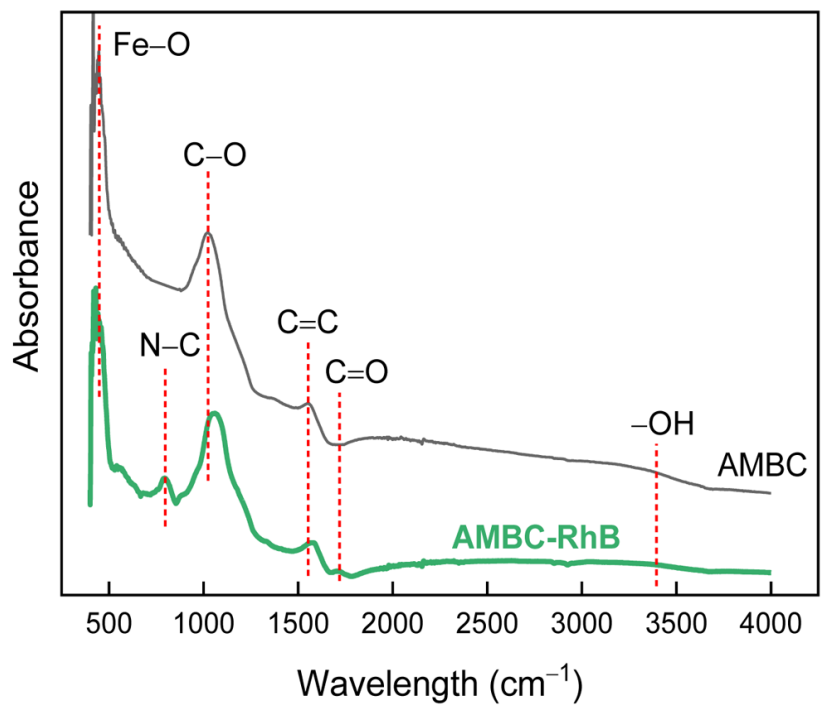

Fig. 6. FTIR spectra for the $\mathrm{AMBC}$ and $\mathrm{AMBC}-\mathrm{RhB}$ composite.

\section{Conclusions}

A novel magnetic biochar (AMBC) was successfully synthesized from $\mathrm{NaOH}$-activated rice straws via a simultaneous carbonization and magnetization method. The magnetization process made the AMBC superior separation nature and adsorption rate, and the alkaline activation promoted the specific surface area and oxygen-containing functions for the adsorbent. These characteristics 
collectively contributed to the favorable adsorption performance of the AMBC towards RhB. Briefly, the adsorption kinetics could be well described by the pseudo-second order kinetics model, and the adsorption isotherms obeyed the Freundlich model.

Thermodynamic parameters indicated the adsorption of $\mathrm{RhB}$ onto the AMBC was spontaneous with a maximum adsorption about $53.66 \mathrm{mg} \mathrm{g}^{-1}$. Although the adsorption performance of the AMBC was strongly affected by the hydro-chemical conditions such as $\mathrm{pH}$, ionic strength and other soluble substances, it could be applied to remove organic dyes at least for $\mathrm{RhB}$ from wastewaters through H-bonds, electrostatic attraction and $\pi-\pi$ stacking. In short, the synthesized AMBC had the advantageous features of low cost, easy synthetization and separation, and considerable adsorption capacity, thus it would be an alternative for water pollution remediation.

\section{Acknowledgments}

This work was financially supported by the National Natural Science Foundation of China (41807379), the Applied Basic Research Foundation of Science and Technology Department of Sichuan Province (2019YJ0340), the Fundamental Research Foundation of China West Normal University (18B022,17E053), the Meritocracy Research Foundation of China West Normal University (17YC143), the National Training Programs of Innovation and Entrepreneurship for Undergraduates (201810638013), and the the Program for Team Scientific Research and Innovation of China West Normal University (CXTD2018-13, CXTD2017-2).

\section{References}

1. Bhatia D, Sharma NR, Singh J, Kanwar RS. Biological methods for textile dye removal from wastewater: A review. Crit. Rev. Env. Sci. Technol. 2017;47:1836-1876.

2. Belpaire C, Reyns T, Geeraerts C, Van Loco J. Toxic textile dyes accumulate in wild European eel Anguilla anguilla. Chemosphere 2015;138:784-791.

3. Chung K. Azo dyes and human health: A review. J. Environ. Sci. Health Part C. 2016;34:233-261.

4. Jain R, Mathur M, Sikarwar S, Mittal A. Removal of the hazardous dye rhodamine $\mathrm{B}$ through photocatalytic and adsorption treatments. J. Environ. Manage. 2007;85:956-964.

5. Oladipo AA, Ifebajo AO. Highly efficient magnetic chicken bone biochar for removal of tetracycline and fluorescent dye from wastewater: two-stage adsorber analysis. J. Environ. Manage. 2018;209:9-16.

6. Bordoloi N, Dey MD, Mukhopadhyay R, Kataki R. Adsorption of Methylene blue and Rhodamine B by using biochar derived from Pongamia glabra seed cover. Water Sci. Technol. 2018;77:638-646.

7. Gollavelli G, Chang C, Ling Y. Facile synthesis of smart magnetic graphene for safe drinking water: heavy metal removal and disinfection control. ACS Sustain. Chem. Eng. 2013;1:462-472.

8. Maleki A, Hamesadeghi U, Daraei $\mathrm{H}$, et al. Amine functionalized multi-walled carbon nanotubes: single and binary systems for high capacity dye removal. Chem. Eng. J. 2017;313:826-835 9. Jang HM, Yoo S, Park S, Kan E. Engineered biochar from pine wood: Characterization and potential application for removal of sulfamethoxazole in water. Environ. Eng. Res. 2019;24:608-617.

10. Omulo G, Banadda N, Kabenge I, Seay J. Optimizing slow pyrolysis of banana peels wastes using response surface methodology. Environ. Eng. Res. 2019;24:354-361.

11. Reddy DHK, Lee S. Magnetic biochar composite: facile synthesis, characterization, and application for heavy metal removal. Colloids Surf., A. 2014;454:96-103.

12. Wang F, Liu L, Liu F, Wang L, Ouyang T, Chang C. Facile one-step synthesis of magnetically modified biochar with enhanced removal capacity for hexavalent chromium from aqueous solution. J. Taiwan Inst. Chem. Eng. 2017;81:414-418.

13. Yap M, Mubarak N, Sahu J, Abdullah E. Microwave induced synthesis of magnetic biochar from agricultural biomass for removal of lead and cadmium from wastewater. J. Ind. Eng. Chem. 2017;45:287-295.

14. Yin Z, Liu Y, Liu S, et al. Activated magnetic biochar by one-step synthesis: Enhanced adsorption and coadsorption for 17ß-estradiol and copper. Sci. Total Environ. 2018;639:1530-1542.

15. Yang F, Zhang S, Sun Y, Du Q, Song J, Tsang DC. A novel electrochemical modification combined with one-step pyrolysis for preparation of sustainable thorn-like iron-based biochar composites. Bioresour. Technol. 2019;274:379-385.

16. Choi Y-K, Jang HM, Kan E, Wallace AR, Sun W. Adsorption of phosphate in water on a novel calcium hydroxide-coated dairy manure-derived biochar. Environ. Eng. Res. 2019;24:434-442.

17. Jin H, Capareda S, Chang Z, Gao J, Xu Y, Zhang J. Biochar pyrolytically produced from municipal solid wastes for aqueous $\mathrm{As}(\mathrm{V})$ removal: adsorption property and its improvement with KOH activation. Bioresour. Technol. 2014;169:622-629.

18. Li B, Yang L, Wang C, et al. Adsorption of Cd(II) from aqueous solutions by rape straw biochar derived from different modification processes. Chemosphere 2017;175:332-340.

19. Jang HM, Yoo S, Park S, et al. Engineered biochar from pine wood: Characterization and potential application for removal of sulfamethoxazole in water. Environ. Eng. Res. 2018;24:608-617.

20. Ren D, Huang B, Yang B, Pan X, Dionysiou DD. Mitigating $17 \alpha$-ethynylestradiol water contamination through binding and photosensitization by dissolved humic substances. J. Hazard. Mater. 2017;327:197-205.

21. Cazetta AL, Pezoti O, Bedin KC, et al. Magnetic activated carbon derived from biomass waste by concurrent synthesis: efficient adsorbent for toxic dyes. ACS Sustain. Chem. Eng. 2016;4:1058-1068.

22. Chu G, Zhao J, Liu Y, et al. The relative importance of different carbon structures in biochars to carbamazepine and bisphenol A sorption. J. Hazard. Mater. 2019;373:106-114.

23. Han B, Zhang M, Zhao D, Feng Y. Degradation of aqueous and soil-sorbed estradiol using a new class of stabilized manganese oxide nanoparticles. Water Res. 2015;70:288-299.

24. Han Y, Cao X, Ouyang X, Sohi SP, Chen J. Adsorption kinetics of magnetic biochar derived from peanut hull on removal of $\mathrm{Cr}(\mathrm{VI})$ from aqueous solution: effects of production conditions and particle size. Chemosphere 2016;145:336-341.

25. Zhou Z, Liu Y, Liu S, et al. Sorption performance and mechanisms of arsenic(V) removal by magnetic gelatin-modified 
biochar. Chem. Eng. J. 2017;314:223-231.

26. Abbas A, Al-Amer AM, Laoui T, et al. Heavy metal removal from aqueous solution by advanced carbon nanotubes: Critical review of adsorption applications. Sep. Purif. Technol. 2016;157: 141-161.

27. Konicki W, Aleksandrzak M, Moszyński D, Mijowska E. Adsorption of anionic azo-dyes from aqueous solutions onto graphene oxide: equilibrium, kinetic and thermodynamic studies. J. Colloid Interface Sci. 2017;496:188-200.

28. Jiang L, Liu Y, Liu S, et al. Fabrication of $\beta$-cyclodextrin/poly (l-glutamic acid) supported magnetic graphene oxide and its adsorption behavior for 17ß-estradiol. Chem. Eng. J. 2017;308: 597-605.

29. Heo J, Yoon Y, Lee G, Kim Y, Han J, Park CM. Enhanced adsorption of bisphenol A and sulfamethoxazole by a novel magnetic CuZnFe2O4-biochar composite. Bioresour. Technol. 2019;281: 179-187.

30. Premarathna K, Rajapaksha AU, Sarkar B, et al. Biochar-based engineered composites for sorptive decontamination of water: A review. Chem. Eng. J. 2019;372:536-550.

31. Dong X, He L, Hu H, Liu N, Gao S, Piao Y. Removal of 17ßestradiol by using highly adsorptive magnetic biochar nanoparticles from aqueous solution. Chem. Eng. J. 2018;352:371-379.

32. Wu Z, Zhong H, Yuan X, at al. Adsorptive removal of methylene blue by rhamnolipid-functionalized graphene oxide from wastewater. Water Res. 2014;67:330-344.

33. Lee M-E, Park JH, Chung JW. Comparison of the lead and copper adsorption capacities of plant source materials and their biochars. J. Environ. Manage. 2019;236:118-124.

34. Laysandra L, Santosa FH, Austen V, et al. Rarasaponin-bentonite-activated biochar from durian shells composite for removal of crystal violet and $\mathrm{Cr}(\mathrm{VI})$ from aqueous solution. Environ. Sci. Pollut. Res. 2018;25:30680-30695.

35. Liu X, Shen F, Qi X. Adsorption recovery of phosphate from aqueous solution by $\mathrm{CaO}-$ biochar composites prepared from eggshell and rice straw. Sci. Total Environ. 2019;666:694-702.

36. Wang Z, Shen D, Shen F, Wu C, Gu S. Kinetics, equilibrium and thermodynamics studies on biosorption of Rhodamine B from aqueous solution by earthworm manure derived biochar. Int. Biodeterior. Biodegrad. 2017;120:104-114.

37. Qiu Y, Zheng Z, Zhou Z, Sheng GD. Effectiveness and mechanisms of dye adsorption on a straw-based biochar. Bioresour. Technol. 2009;100:5348-5351.

38. Jia Y, Zhang Y, Fu J, et al. A novel magnetic biochar/MgFe-layered double hydroxides composite removing $\mathrm{Pb}^{2+}$ from aqueous solution: Isotherms, kinetics and thermodynamics. Colloids Surf., A. 2019;567:278-287.

39. Jiang C, Wang X, Qin D, et al. Construction of magnetic lignin-based adsorbent and its adsorption properties for dyes. J. Hazard. Mater. 2019;369:50-61.

40. Deng J, Chen Y, Lu Y, et al. Synthesis of magnetic $\mathrm{CoFe}_{2} \mathrm{O}_{4}$ /ordered mesoporous carbon nanocomposites and application in Fenton-like oxidation of rhodamine B. Environ. Sci. Pollut. Res. 2017;24:14396-14408.

41. Chen B, Liu Y, Chen S, Zhao X, Yue W, Pan X. Nitrogen-rich core/shell magnetic nanostructures for selective adsorption and separation of anionic dyes from aqueous solution. Environ. Sci-Nano. 2016;3:670-681.

42. Jiang L, Liu Y, Zeng G, et al. Adsorption of estrogen contaminants (17 $\beta$-estradiol and $17 \alpha$-ethynylestradiol) by graphene nanosheets from water: Effects of graphene characteristics and solution chemistry. Chem. Eng. J. 2018;339:296-302.

43. Ren D, Huang B, Yang B, Chen F, Pan X, Dionysiou DD. Photobleaching alters the photochemical and biological reactivity of humic acid towards $17 \alpha$-ethynylestradiol. Environ. Pollut. 2017;220:1386-1393.

44. Jiang L, Liu Y, Zeng G, et al. Removal of 17ß-estradiol by few-layered graphene oxide nanosheets from aqueous solutions: External influence and adsorption mechanism. Chem. Eng. J. 2016;284:93-102.

45. Wang J, Chen Z, Chen B. Adsorption of polycyclic aromatic hydrocarbons by graphene and graphene oxide nanosheets. Environ. Sci. Technol. 2014;48:4817-4825. 